\title{
Protective immunity against atherosclerosis carried by $B$ cells of hypercholesterolemic mice
}

\section{Giuseppina Caligiuri, ${ }^{1}$ Antonino Nicoletti, ${ }^{1,2}$ Bruno Poirier, ${ }^{2}$ and Göran K. Hansson ${ }^{1}$}

${ }^{1}$ Center for Molecular Medicine and Department of Medicine, Karolinska Institute, Stockholm, Sweden

${ }^{2}$ Institut National de la Santé et de la Recherche Médicale U430, Hôpital Broussais, Paris, France

Address correspondence to: Göran K. Hansson, Center for Molecular Medicine, L8:03 Karolinska Hospital, SE-17176 Stockholm, Sweden.

Fax: 46-8-313147; E-mail: Goran.Hansson@cmm.ki.se.

Giuseppina Caligiuri and Antonino Nicoletti contributed equally to this work.

Received for publication May 6, 1999, and accepted in revised form January 10, 2002.

\begin{abstract}
Atherosclerosis is characterized by vascular inflammation and associated with systemic and local immune responses to oxidized LDL (oxLDL) and other antigens. Since immunization with oxLDL reduces atherosclerosis, we hypothesized that the disease might be associated with development of protective immunity. Here we show that spleen-associated immune activity protects against atherosclerosis. Splenectomy dramatically aggravated atherosclerosis in hypercholesterolemic apoE knockout $\left(\mathrm{apoE}^{\circ}\right)$ mice. Transfer of spleen cells from atherosclerotic apoE $\mathrm{E}^{\circ}$ mice significantly reduced disease development in young $\mathrm{apoE}^{\circ}$ mice. To identify the protective subset, donor spleen cells were divided into $B$ and $T$ cells by immunomagnetic separation before transfer. Protection was conferred by $\mathrm{B}$ cells, which reduced disease in splenectomized apoE $\mathrm{E}^{\circ}$ mice to one-fourth of that in splenectomized $\mathrm{apoE}^{\circ}$ controls. Protection could also be demonstrated in intact, nonsplenectomized mice and was associated with an increase in antibody titers to oxLDL. Fewer CD4 ${ }^{+} \mathrm{T}$ cells were found in lesions of protected mice, suggesting a role for T-B cell cooperation. These results demonstrate that B cell-associated protective immunity develops during atherosclerosis and reduces disease progression.
\end{abstract}

J. Clin. Invest. 109:745-753 (2002). DOI:10.1172/JCI200207272.

\section{Introduction}

Atherosclerosis is characterized by focal arterial lesions containing cholesterol, fibrosis, and inflammatory infiltrates (1). The latter consist mainly of macrophages and $\mathrm{T}$ lymphocytes, many of which are immunoreactive against oxidized low density lipoprotein (oxLDL) $(2,3)$. Patients with atherosclerosis exhibit systemic antibody responses against oxLDL (4, 5), heat shock proteins (6), Chlamydia pneumoniae (7), and other antigens, but the role of adaptive immunity in atherosclerosis has remained unclear. The construction of a mouse strain that develops hypercholesterolemia and atherosclerosis by targeted gene deletion of the $A p o E$ gene $\left(\mathrm{apoE}^{\circ}\right)(8,9)$ has permitted detailed studies of disease mechanisms. Immunodeficient apoE ${ }^{\circ} \times \mathrm{RAG}^{-1 /-}$ and $\mathrm{apoE}^{\circ}$ SCID mice, which both lack $\mathrm{T}$ and $\mathrm{B}$ cells, apoE ${ }^{\circ}$ mice lacking receptors for the Th1 cytokine IFN- $\gamma$, and $\mathrm{apoE}^{\circ}$ mice that lack the CD40 ligand all develop smaller lesions than do immunocompetent $\mathrm{apoE}^{\circ}$ mice (10-13). Treatment of immunocompetent $\mathrm{apoE}^{\circ}$ mice with immunomodulating doses of polyclonal IgG or with anti-CD40 ligand antibodies also reduces disease development $(14,15)$. Transfer of $\mathrm{CD}^{+} \mathrm{T}$ cells into apoE ${ }^{\circ} \times$ SCID mice aggravates disease, implying that the $\mathrm{CD}^{+} \mathrm{T}$ cells are a proatherogenic subset (13). While all these data point to a proatherogenic role for adaptive immunity, the finding that immunization with oxLDL reduces lesions (16-20) suggests that protective immunity may also occur.

The concepts of atheroprotective and proatherogenic immunity imply that different effector mechanisms may affect disease development in opposite directions. For instance, the reduced atherosclerosis in the IFN- $\gamma$ receptor knockout apoE ${ }^{\circ}$ mice (11), increased atherosclerosis after $\mathrm{CD}^{+} \mathrm{T}$ cell transfer (13), and increased fatty streak formation in IL-10 knockout mice $(21,22)$ suggest that Th1 cells accelerate atherosclerosis. Studies of experimental autoimmune encephalomyelitis have shown that B cells may protect against disease by eliciting Th1-inhibitory pathways (23). B cells might also counteract disease by producing antibodies to autoantigens such as oxLDL, leading to elimination of antigen.

$B$ cells producing anti-oxLDL antibodies are readily isolated from the spleens of nonimmunized $a p o E^{\circ}$ mice and can be used for generation of monoclonal $\mathrm{B}$ cell hybridomas (24). In fact, the spleen harbors approximately $25 \%$ of all lymphocytes, including the largest pool of memory B cells (25). It plays an important role in $\mathrm{B}$ cell maturation and the development of humoral immunity, especially for blood-borne antigens such as modified lipoproteins (26), and also regulates certain aspects of cell-mediated immunity (27). 
Splenectomy therefore modulates the immune response to both self and nonself antigens (28).

In the present study, we report that transfer of B cells from atherosclerotic apoE ${ }^{\circ}$ mice reduced disease development in young $\mathrm{apo}^{\circ}$ mice. In contrast, splenectomy severely aggravated atherosclerosis. This implies that protective immunity develops during atherosclerosis in apoE ${ }^{\circ}$ mice and can be transferred to protect diseaseprone recipients from disease.

\section{Methods}

Animals. Male $\mathrm{apoE}^{\circ}$ mice (8) were bred to a ten-generation backcross against C57BL/6J at M\&B (Ry, Denmark). At 6 weeks of age, anesthetized mice were subjected to either sham operation or splenectomy $(n=4$ to 7 mice per group; see Table 1 and figure legends). In certain experiments, splenectomy or sham operation was immediately followed by transfer through the tail vein of cells from syngenic donors (see below). Key experiments were repeated three times, and a total of 107 mice were used for analysis of atherosclerosis. After surgery, mice were maintained for 12 weeks in isolator units with filtered air, sterilized beddings, and sterilized Western diet with $0.15 \%$ cholesterol (29) and treated with a cocktail of antibiotics (sulfametoxine and trimethoprim, Borgal; Hoechst, Frankfurt, Germany). The perioperative mortality was $8 \%$ and no infections were registered during daily examinations by the staff, during weekly examinations by a veterinarian, or at autopsy. Mice were sacrificed under anesthesia, sera harvested, and cell suspensions obtained from the inguinal, axillary, cervical, and paraaortic lymph nodes. The heart and the aorta were mounted in OCT embedding medi$\mathrm{um}$, frozen in carbon dioxide, and stored at $-85^{\circ} \mathrm{C}$.

Isolation of spleen cells. Spleens were collected from donor mice and cells harvested through $100-\mu \mathrm{m}$ nylon filters. Erythrocytes were lysed and nucleated cells were washed twice, counted, suspended in culture medium, and injected into recipient mice within 3 hours. The spleen cell preparations contained $16.7 \% \pm 2.5 \% \mathrm{CD}^{+} \mathrm{T}$ cells, $43.1 \%$ $\pm 1.1 \% \mathrm{CD} 19^{+} \mathrm{B}$ cells, and $40.1 \%$ non-B, non- $\mathrm{T}$ cells. $\mathrm{B}$ and $\mathrm{T}$ cells were isolated by negative selection after an initial adherence step with cells in culture medium on tissue culture plastic dishes for 30 minutes at $37^{\circ} \mathrm{C}$. Biotin-conjugated anti-CD3 and anti-CD19 antibodies were added to non-adherent cells, which were eliminated by using paramagnetic avidin-coated beads, and MidiMax columns (Becton Dickinson Immunocytometry Systems, Mountain View, California, USA). Immunomagnetic selection was repeated twice, and unbound cells were washed and injected into the recipient. The purity of isolated $\mathrm{T}$ and $\mathrm{B}$ cells was always $>98 \%$ by FACS in the $\mathrm{CD}^{2} 5^{+} \times$lymphocyte (FSC/SSC) gate. The T cell preparations contained $60 \% \pm 3 \% \mathrm{CD}^{+}$and $40 \% \pm 4 \% \mathrm{CD}^{+}$cells.

Transfer of cells. Whole $\left(\sim 60 \times 10^{6}\right)$ or selected $\left(\sim 20 \times 10^{6}\right)$ spleen cell suspensions in a fixed volume of $500 \mu \mathrm{l}$ sterile PBS were slowly injected into the tail veins of anesthetized recipient mice using a 27-gauge needle mounted on a 1-ml syringe.
LDL preparations and serum assays. LDL ( $d=1.019-1.063$ $\mathrm{g} / \mathrm{ml}$ ) was obtained under sterile conditions by ultracentrifugation of human plasma collected from ten donors. Malondialdehyde (MDA) modification was performed as described (30), and the extent of modification was assessed by fluorimetry at 400 and $470 \mathrm{~nm}$. The titers of specific anti-MDA-LDL antibodies were measured by ELISA using alkaline phosphatase-labeled anti-mouse IgG (30) and calculated as described (31). Serum levels of IgG isotypes, IFN- $\gamma$, and IL- 4 were analyzed by ELISA (30) (PharMingen, San Diego, California, USA) and serum cholesterol was analyzed by a cholesterol oxidase kit (Boehringer Mannheim GmbH, Mannheim, Germany).

FACS analysis. Lymph node cells from individual mice were stained with the fluorescent antibodies CD45-Cy, CD3-FITC, CD19-PE, CD4-Cy, and CD8-PE (PharMingen) using a triple-staining immunofluorescence protocol and a FACSCalibur (Becton Dickinson Immunocytometry Systems) flow cytometer. Five thousand lymphocytes identified by light scatter and CD45 staining were analyzed in each sample.

Cell proliferation analysis. Lymph node cells (inguinal, axillary, and cervical from individual mice) were incubated for 3 days with concanavalin A (Con A) $(2.5$ $\mu \mathrm{g} / \mathrm{ml})$ followed by Con $\mathrm{A}$ and ${ }^{3} \mathrm{H}$-thymidine for 18 hours and analyzed by $\beta$ counting (14).

Evaluation of spleen cell transfer and homing. Two different approaches were used to study homing of transferred cells. Spleen cells isolated from apo ${ }^{\circ}$ mice were labeled with the CellTracker CM-DiI kit (Molecular Probes, Europe BV, Leiden, The Netherlands). Six splenectomized and three sham-operated $a \mathrm{poE}^{\circ}$ mice received $60 \times 10^{6}$ DiI-labeled spleen cells by intravenous injection. Four weeks later, cell suspensions were obtained from the inguinal, mesenteric, and paraaortic lymph nodes and, when present, the spleen. Cells from individual mice were stained with anti-CD3-FITC and anti-CD45-Cy, and $\mathrm{DiI}^{+}$cells (FL2 channel) were detected in the lymphocyte population gated on the FSC/SSC scatter and among the CD $45^{+}$(i.e., leukocyte) and the $\mathrm{CD}^{+}$populations. Six non-reconstituted splenectomized $\mathrm{apoE}^{\circ}$ mice were used as controls.

Four $\mathrm{apo}^{\circ}$ splenectomized and four sham-operated mice were injected each with $70 \times 10^{6}$ spleen cells from apo $\mathrm{E}^{\circ}$ mice transgenic for the thymidine kinase (TK). $\mathrm{apoE}^{\circ}$ mice were crossed with Ep TK mice (C57BL/6J background), in which the Herpes simplex TK gene is controlled by the human CD4 promoter. This results in TK expression exclusively in mature $T$ cells (32) and offers the possibility of tracking the injected cells either by PCR amplification of genomic DNA, thus detecting all transferred cells, or by amplifying mRNA by reverse transcription-PCR (RT-PCR), which detects transferred $\mathrm{T}$ cells. Four weeks after reconstitution, samples were harvested from organs and blood. The same amounts of tissue (by weight) were used for extraction of genomic DNA and mRNA (DNeasy and RNeasy kits; QIAGEN GmbH, Hilden, 
Germany). The genesis and phenotype of the apoE ${ }^{\circ}$ TK mice will be described in greater detail elsewhere. Morphology and immunohistochemistry. Serial cryostat sections were cut from the proximal $1 \mathrm{~mm}$ of the aortic root (14). Hematoxylin/oil red O-stained sections were used for computer-assisted morphometry, and avidin-biotinperoxidase visualization of sections reacted with cell-specific monoclonals to CD4, CD8, and I-A ${ }^{\mathrm{b}}$ (PharMingen) was employed for cell counting (14). An alkaline phosphatase-conjugated monoclonal anti- $\alpha$ SM-actin antibody (Sigma Chemical Co., St. Louis, Missouri, USA) was used to detect smooth muscle cells. Fibrous cap formation was scored in hematoxylin/oil red O-stained sections (-, no smooth muscle cap;,$+<50 \%$ of lesion covered by cap;,$++>50 \%$ of lesion covered by cap) based on $\alpha$ SMactin staining. The mean lesion size was determined after measuring ten sections collected at every $100 \mu \mathrm{m}$ over a $1-\mathrm{mm}$ segment of the aortic root (14). For each section, images were captured in a microcomputer and the surface areas of the lesion(s) and of the entire vessel were measured. The fraction area of lesion (\%) is the ratio between the cross-section area occupied by lesion and the total vessel cross-section area. This compensates for variations in the section angle between tissue sections (14). Immunohistochemical data were obtained by manual counting of total cells and all antibody-stained cells in all lesions of one section per mouse. The analysis was validated when another investigator recounted the slides. Both investigators were blinded with regard to the group and treatment from which the slides originated, and the inter-investigator difference was less than $15 \%$.

Genomic DNA analysis. DNA was normalized between samples based on absorbance at $260 \mathrm{~nm}$ and amplified by PCR in a mastermix containing $67 \mathrm{mM}$ Tris- $\mathrm{HCl}, 16$ $\mathrm{mM}\left(\mathrm{NH}_{4}\right)_{2} \mathrm{SO}_{4}, 0.1 \%$ Tween-20, $0.75 \mathrm{mM} \mathrm{MgCl}_{2}, 0.2$ $\mathrm{mM}$ dNTP, 1\% vol/vol dimethylsulfoxide, $40 \mathrm{U} / \mathrm{ml}$ Euroblue Taq polymerase (Eurobio SA, Les Ulis, France), $2 \mu \mathrm{M}$ primers (upper: $5^{\prime}$-GGA-CGC-GGC-GGTGGT-AAT-GAC-AAG-3'; lower: 5'-GCG-CGG-CCG-GGTAGC-ACA-GG-3'). The kinetics of the reaction were characterized by analyzing liver DNA after 30, 34, 38, 40, 42, 44, 46, and 48 PCR cycles. A 37-cycle PCR was chosen for the subsequent analyses since sufficient reaction product was produced to permit easy detection while the reaction was still in an exponential phase (see Results). In all these analyses, the first PCR cycle started with 2.5 minutes in a hot block at $92^{\circ} \mathrm{C}$ followed by 1 minute at $61^{\circ} \mathrm{C}$ and 2 minutes at $72^{\circ} \mathrm{C}$. The ensuing 36 cycles consisted of 30 seconds at $92^{\circ} \mathrm{C}, 1$ minute at $61^{\circ} \mathrm{C}$, and 2 minutes at $72^{\circ} \mathrm{C}$ in a Robocycler (Stratagene, La Jolla, California, USA). Densitometric analysis of the amplified products (182 bp) provided the amount of the TK genomic DNA (arbitrary units), which is expected to be proportional to the number of apoE ${ }^{\circ} \mathrm{TK}$ cells present in each tissue sample.

$R T$-PCR. RNA was reverse-transcribed as described previously (30). cDNA was amplified with primers specific for GAPDH $(2 \mu \mathrm{M}$; upper: 5 '-GTG-AAG-GTC-GGAGTC-AAC-G-3'; lower: 5'-GGT-GAA-GAC-GCC-AGT-GGA-
CTC-3') with the same PCR settings as described for genomic DNA. Densitometry of the amplified products was used to normalize the amount of DNA. New PCR reactions were performed with the primers for GAPDH and TK $(2 \mu \mathrm{M})$, respectively, using the same PCR settings. The kinetics of the reactions were evaluated by amplifying thymus cDNA for 24, 26, 28, 32, and 36 cycles using GAPDH primers and for 30 to 48 cycles using TK primers. A 27-cycle PCR was selected for GAPDH, while 37 cycles were found to be optimal for TK. A densitometric analysis was performed on the amplified TK (182 bp) and GAPDH (299 bp) products, and results are expressed as TK/GAPDH ratio. This measure is expected to reflect the proportion of $\mathrm{apoE}^{\circ}$ TK spleen T cells in the cell population of each tissue.

Statistical analysis. Results are expressed as means \pm SEM. Continuous data were analyzed by one-factor ANOVA followed by Fisher's test for comparisons between means. Data scores for fibrous caps were analyzed by Wilcoxon's sign rank test. Differences between groups were considered significant if $P$ was less than 0.05 .

\section{Results}

Increased atherosclerosis in splenectomized apo $E^{\circ}$ mice. ApoE ${ }^{\circ}$ mice were splenectomized or sham-operated at 6 weeks of age and then fed a Western diet for 3 months. No infections occurred, and there was no difference in body weight or mitogen-induced $\mathrm{T}$ or B cell proliferation between treatment groups (data not shown). Atherosclerotic lesions were quantified in sections from the root of the aorta. Compared with sham-operated $\mathrm{apoE}^{\circ}$ controls, lesions were increased significantly in splenectomized mice (Figures 1 and 2; Table 1). Serum cholesterol levels remained unchanged after splenectomy (Table 1). In contrast, IgG antibody titers to LDL coupled with the oxidation-induced epitope MDA were reduced by splenectomy but not by sham operation (Figure 3). These data show that the spleen contains antiatherogenic activity and suggest that its effect on lesion formation is dependent on immunity rather than cholesterol metabolism.

Long-term survival of spleen lymphocytes in recipient organs. To test this hypothesis, transfer experiments were performed using immunocompetent spleen cells that could be tracked in the recipient. In the first experiment, spleen cells of $\mathrm{apoE}^{\circ}$ mice were labeled with DiI fluorochrome immediately before transfer into recipients. Among transferred cells, $16.7 \% \pm 2.5 \%$ were $\mathrm{CD}^{+} \mathrm{T}$ cells and $43.1 \% \pm 1.1 \% \mathrm{CD} 19^{+} \mathrm{B}$ cells. Four weeks later, $\mathrm{DiI}^{+}$ cells were detected by FACS analysis of lymph node cells from recipients (Table 2). Approximately one in 400 cells was $\mathrm{DiI}^{+}$and therefore from the donor population. Double staining of light scatter-gated lymphocytes indicated that $0.085 \% \pm 0.004 \%$ of all cells were $T$ cells, and $0.22 \% \pm 0.02 \%$ were $\mathrm{B}$ cells. This analysis provided evidence for long-term homing of transferred cells to lymphoid tissue. However, it was not sensitive enough to permit detection of the lower frequency of cells homing to other organs. 


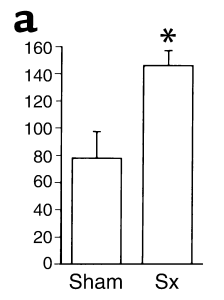

b
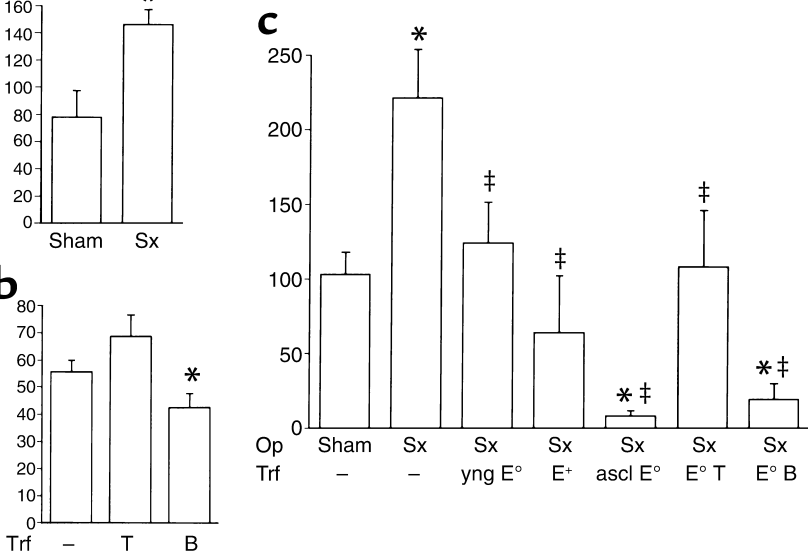

\section{Figure 1}

Effect of splenectomy and cell transfer on atherosclerotic lesions in apo $E^{\circ}$ mice. Morphometric analysis of lesion size (cross-section area at the aortic root occupied by lesion, $\times 10^{3} \mu \mathrm{m}^{2}$, mean \pm SEM). Data are from a representative experiment, and additional data summarizing all experiments are displayed in Table 1. (a) Splenectomy (Sx) increases lesion formation. Lesion size 12 weeks after Sx was significantly increased $(P<0.05, n=6$ per group) when compared with sham-operated $\mathrm{apoE}^{\circ}$ mice. (b) Transfer (Trf) of B cells but not $\mathrm{T}$ cells from atherosclerotic apoE ${ }^{\circ}$ mice reduces lesion formation in sham-operated apoE ${ }^{\circ}$ mice. Lesions in the latter $(n=6)$ were significantly larger than those in B cell-transferred mice $(P<0.05, n=7)$ but not different from those in T cell-transferred ones $(n=5)$. (c) Spleen cell transfer rescues apo $E^{\circ}$ mice from the proatherogenic effect of splenectomy. Average lesion sizes are shown for sham-operated $(n=8)$ and $S x(n=7)$ apoE $^{\circ}$ mice, and for $S x$ apo $E^{\circ}$ mice who received spleen cell transfer from young apo $\mathrm{E}^{\circ}$ mice (yng $\mathrm{E}^{\circ}, n=4$ recipients), wild-type $\mathrm{C} 57 \mathrm{BL} / 6 \mathrm{~J}$ mice $\left(\mathrm{E}^{+}, n=4\right)$, or atherosclerotic apo $\mathrm{E}^{\circ}$ mice (ascl $\left.\mathrm{E}^{\circ}, n=6\right)$ or purified spleen $\mathrm{T}$ cells $\left(\mathrm{E}^{\circ} \mathrm{T}, n=4\right.$ recipients) or $\mathrm{B}$ cells $\left(\mathrm{E}^{\circ} \mathrm{B}, n=4\right)$ from atherosclerotic apoE ${ }^{\circ}$ mice. ${ }^{*}$ Significantly different from sham, $P<0.05$; ‡significantly different from $\mathrm{Sx}, P<0.05$. Op, operation.

In a second experiment, spleen cells were therefore transferred from transgenic mice carrying the TK gene under the $\mathrm{CD} 4$ promoter, which drives gene expression selectively in $\mathrm{T}$ cells. Both donors and recipients had a $\mathrm{C} 57 \mathrm{BL} / 6 \mathrm{~J}\left(\mathrm{H}-2^{\mathrm{b}}\right)$ background, and splenectomized as well as sham-operated recipients were used in the experiment. Long-term homing of lymphocytes was estimated by analyzing TK mRNA expression in various organs. This approach permitted a highly sensitive, semiquantitative assessment of homing. The majority of $\mathrm{TK}^{+} \mathrm{T}$ cells were found in the lungs and thymus, and in the sham-operated mice, a large proportion of the cells was also present in the spleen (Figure 4). Significant $\mathrm{T}$ cell TK expression was also detected in the lymph nodes, kidney, liver, and aorta, in all cases with higher levels in the splenectomized mice (Figure 4). The extent of $\mathrm{T}$ cell $\mathrm{TK}$ expression in lungs and thymus was higher in sham-operated than in splenectomized mice. Significant $\mathrm{T}$ cell TK expression was found in the heart and blood of splenectomized but not sham-operated mice (Figure 4). These data are in line with recent studies reporting survival and expansion of memory $\mathrm{T}$ cells after transfer into antigen-exposed hosts (33). Our own data show that transferred spleen lymphocytes home to lymphoid and other organs, where they remain viable for several weeks, and that splenectomy increases the amount of transferred cells circulating in the blood and homing to the heart, aorta, and kidney.

Spleen cell transfer reduces atherosclerosis in apo $E^{\circ}$ mice. To evaluate the effect of spleen cell transfer on atherosclerosis, spleen cell transfer experiments were performed between $\mathrm{apoE}^{\circ}$ mice that were MHC-identical and on a C57BL/6 $\left(\mathrm{H}-2^{\mathrm{b}}\right)$ background. Spleen cells were obtained from either young (6-week-old) apoE ${ }^{\circ}$ mice that had not yet developed disease; atherosclerotic, old (20-week-old) $\mathrm{apoE}^{\circ}$ mice that had been fed a proatherogenic diet for 12 weeks; or wild-type C57BL/6J mice. Recipient apoE ${ }^{\circ}$ mice were splenectomized, injected with donor spleen cells, and then fed the proatherogenic diet for 12 weeks. Spleen cell transfer did not affect total Ig levels or $\mathrm{T}$ cell reactivity to Con A mitogen (data not shown). Reduced serum cholesterol levels were seen in $\mathrm{apoE}^{\circ}$ mice that received spleen cells from apoE ${ }^{+++}$C57BL/6 mice (Table 1). Serum cholesterol tended to be lower also in mice receiving spleen cells from atherosclerotic apo ${ }^{\circ}$ mice, but the trend was not statistically significant.

Analysis of lesion data showed significant effects of several treatments. All these data were therefore subjected to ANOVA followed by comparisons
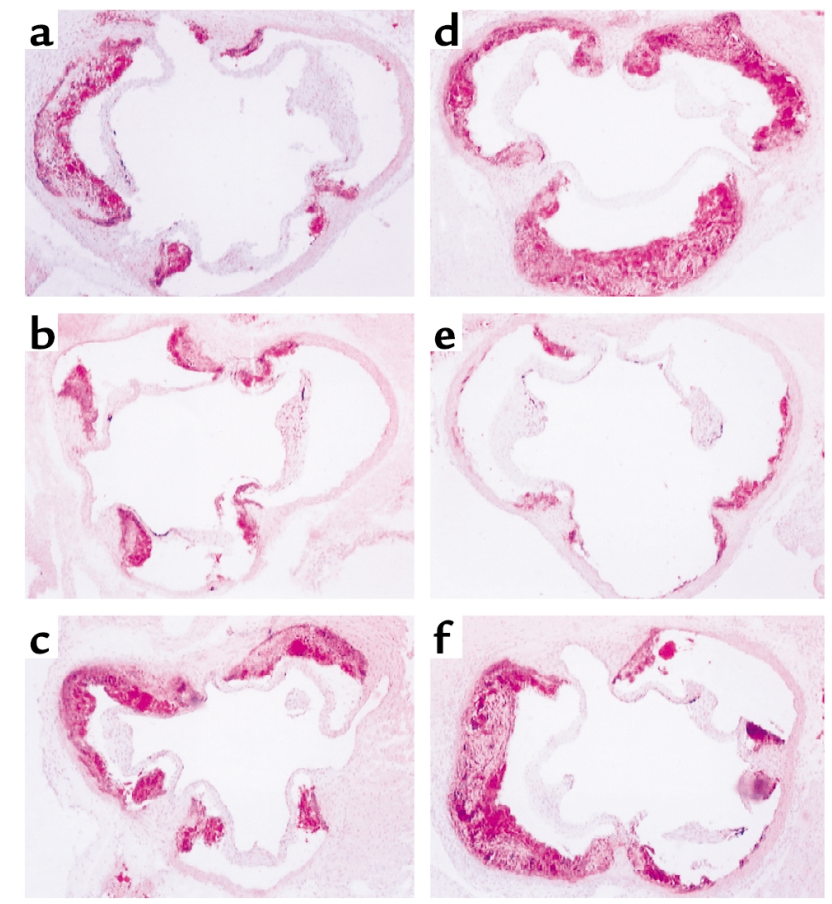

\section{Figure 2}

Effect of splenectomy and cell transfer on atherosclerotic lesions in the aortic root of apo ${ }^{\circ}$ mice. Hematoxylin/oil red O-stained lesions from the level of the aortic cusps, $\times 50$. (a) Sham-operated mouse. (b) Sham-operated mouse that received B cells from an atherosclerotic mouse. (c) Sham-operated mouse that received T cells from an atherosclerotic mouse. (d) Splenectomized mouse. (e) Splenectomized mouse that received B cells from an atherosclerotic mouse. (f) Splenectomized mouse that received $T$ cells from an atherosclerotic mouse. 
Table 1

Characteristics of experimental groups

\begin{tabular}{|c|c|c|c|c|c|c|c|}
\hline Group & $n$ & $\begin{array}{l}\text { Weight at } \\
\text { sacrifice }(\mathrm{g})\end{array}$ & $\begin{array}{l}\text { Cholesterol } \\
(\mathrm{mmol} / \mathrm{l})\end{array}$ & $\begin{array}{l}\text { Surface vessel } \\
\text { (\%control) }\end{array}$ & $\begin{array}{l}\text { Surface lesion } \\
\text { (\%control) }\end{array}$ & $\begin{array}{c}\text { Fraction area of lesion } \\
\text { (\%control) }\end{array}$ & $\begin{array}{l}\text { Aortic fibro- } \\
\text { fatty plaques }\end{array}$ \\
\hline$E^{\circ}$ Sham & 14 & $31.4 \pm 0.9$ & $34.0 \pm 1.7$ & $100.0 \pm 3.4$ & $100.0 \pm 11.3$ & $100.0 \pm 9.5$ & ++ \\
\hline$E^{\circ} S x$ & 16 & $31.4 \pm 0.8$ & $31.6 \pm 3.4$ & $111.5 \pm 5.1$ & $286.3 \pm 37.1^{\mathrm{B}}$ & $260.2 \pm 24.4^{B}$ & ++ \\
\hline$E^{\circ} S x+$ Young $E^{\circ}$ & 9 & $31.3 \pm 0.9$ & $31.5 \pm 4.7$ & $117.3 \pm 6.1^{\mathrm{A}}$ & $146.5 \pm 32.6^{\mathrm{D}}$ & $122.8 \pm 22.6^{\mathrm{E}}$ & + \\
\hline $\mathrm{E}^{\circ} \mathrm{S} x+\mathrm{B} 6$ & 9 & $28.3 \pm 0.7^{\mathrm{A}, \mathrm{C}}$ & $21.3 \pm 6.9^{A}$ & $107.8 \pm 5.5$ & $91.0 \pm 30.4^{\mathrm{E}}$ & $87.4 \pm 28.6^{\mathrm{E}}$ & + \\
\hline $\mathrm{E}^{\circ} \mathrm{S} x+$ Old $\mathrm{E}^{\circ}$ & 12 & $29.8 \pm 0.7$ & $25.0 \pm 4.3$ & $102.2 \pm 4.8$ & $50.7 \pm 16.3^{\mathrm{E}}$ & $46.3 \pm 13.6^{\mathrm{A}, \mathrm{E}}$ & - \\
\hline $\mathrm{E}^{\circ} \mathrm{S} x+$ Old $\mathrm{E}^{\circ} \mathrm{B}$ & 9 & $29.0 \pm 0.8$ & $22.9 \pm 8.6$ & $111.0 \pm 4.2$ & $76.6 \pm 14.7^{\mathrm{E}}$ & $70.8 \pm 13.3^{\mathrm{E}}$ & - \\
\hline $\mathrm{E}^{\circ} \mathrm{S} x+$ Old $\mathrm{E}^{\circ} \mathrm{T}$ & 10 & $32.8 \pm 1.0$ & $33.8 \pm 4.6$ & $109.8 \pm 5.9$ & $136.7 \pm 31.3^{\mathrm{E}}$ & $122.8 \pm 23.0^{\mathrm{E}}$ & ++ \\
\hline$E^{\circ}$ Sham + Old $E^{\circ} B$ & 7 & $28.5 \pm 2.1^{\mathrm{A}}$ & $27.0 \pm 4.6$ & $98.9 \pm 2.6$ & $76.2 \pm 9.0^{\mathrm{E}}$ & $77.3 \pm 9.2 \mathrm{~A}, \mathrm{E}$ & + \\
\hline $\mathrm{E}^{\circ}$ Sham + Old E $\mathrm{E}^{\circ} \mathrm{T}$ & 5 & $30.0 \pm 1.2$ & $26.2 \pm 3.3$ & $108.6 \pm 4.3$ & $123.7 \pm 14.2^{\mathrm{D}}$ & $115.2 \pm 13.8^{\mathrm{E}}$ & ++ \\
\hline
\end{tabular}

Mice were weighed at the time of sacrifice, serum cholesterol was assayed and lesions analyzed in cross-sections from the aortic root. Morphometric data are expressed as \% of control and were normalized to the sham control of each experiment. Average values over a 1-mm segment were calculated as indicated in Methods. Fraction area of lesion is (100× surface lesion)/surface vessel, \%. This calculation compensates for oblique sectioning (see ref. 14$)$. Fibrofatty plaques were defined as lesions with $\alpha$-SM-actin caps (++ denotes cap formation in $>50 \%$ of lesions, + indicates cap formation in $<50 \%$ of lesions, and indicates fatty streaks that lack fibrous caps). Data are means \pm SEM. Sx, splenectomy. ${ }^{A} P<0.05$ and ${ }^{B} P<0.0001$, respectively, vs. sham. ${ }^{C} P<0.05$, $\mathrm{D} P<0.001$, and $\mathrm{E} P<0.0001$, respectively, vs. Sx.

between groups using Fisher's test. Only those differences that were statistically significant in these analyses are described and discussed below. Transfer of spleen cells from either wild-type or nonatherosclerotic apoE ${ }^{\circ}$ mice reduced the size of fibrofatty atherosclerotic plaques to that in sham-operated $a \mathrm{poE}^{\circ}$ mice and thus rescued the recipients from the proatherogenic effect of splenectomy (Figure 1c). Spleen cells from atherosclerotic $\mathrm{apoE}^{\circ}$ mice not only rescued but endowed further protection of recipient mice, the lesions of which were only $40-50 \%$ the size of the lesions of sham-operated mice (Figure 1c). These small lesions were mainly composed of foam cells and lacked $\alpha \mathrm{SM}$-actin ${ }^{+}$smooth muscle caps (Figures 2 and 5 ; Table 1). In contrast, fibrofatty plaques were found in sham-operated controls and, to a lesser extent, also in mice rescued with spleen cells from either wild-type mice or nonatherosclerotic apoE ${ }^{\circ}$ mice (Table 1 ). Thus, both disease progression and the growth of individual lesions were inhibited by spleen cells transferred from atherosclerotic mice. Circulating antibodies to MDA-LDL were significantly reduced by splenectomy and normalized by reconstitution with spleen cells from atherosclerotic apoE ${ }^{\circ}$ mice (Figure 3). These data suggest that protection from atherosclerosis was associated with specific immune responses to oxLDL.

$B$ cells from apo $E^{\circ}$ mice inhibit atherosclerosis. To identify the protective subset of cells, $\mathrm{T}$ and $\mathrm{B}$ cells were isolated from the spleens of atherosclerotic $\mathrm{apoE}^{\circ}$ mice by immunomagnetic separation and injected into splenectomized young, nonatherosclerotic apoE ${ }^{\circ}$ mice, which were fed the proatherogenic diet for 12 weeks. While $\mathrm{CD}^{+} \mathrm{T}$ cells reduced the disease-aggravating effect of splenectomy, B cells actually protected mice from developing disease (Figure 1; Table 1). This suggests that $\mathrm{B}$ cells of apoE ${ }^{\circ}$ mice carry atheroprotective immunity. Lesions in $\mathrm{B}$ cell recipients were all of the fatty streak type, while those in splenectomized mice were advanced fibrofatty plaques and those in mice receiving $\mathrm{T}$ cells were a mixture of fatty streaks and fibrofatty plaques (Figures 2 and 5; Table 1).

To determine whether splenectomy was required to demonstrate an atheroprotective effect of $B$ cells from atherosclerotic mice, spleen cells from 20 -week-old apoE ${ }^{\circ}$ mice were fractionated into $\mathrm{T}$ and $\mathrm{B}$ cells and transferred into $\mathrm{apoE}^{\circ}$ recipients that had not been splenectomized. All recipients were fed the proatherogenic diet for 12 weeks before lesions were analyzed. As shown in Figure $1 \mathrm{~b}$, transfer of $\mathrm{B}$ cells but not $\mathrm{T}$ cells reduced lesion size in sham-operated $\mathrm{apoE}^{\circ}$ mice. As expected, the impact on atherosclerosis was smaller than in the splenectomized mice, but it was statistically significant in the sham-operated ones as well (Figure 1; Table 1).

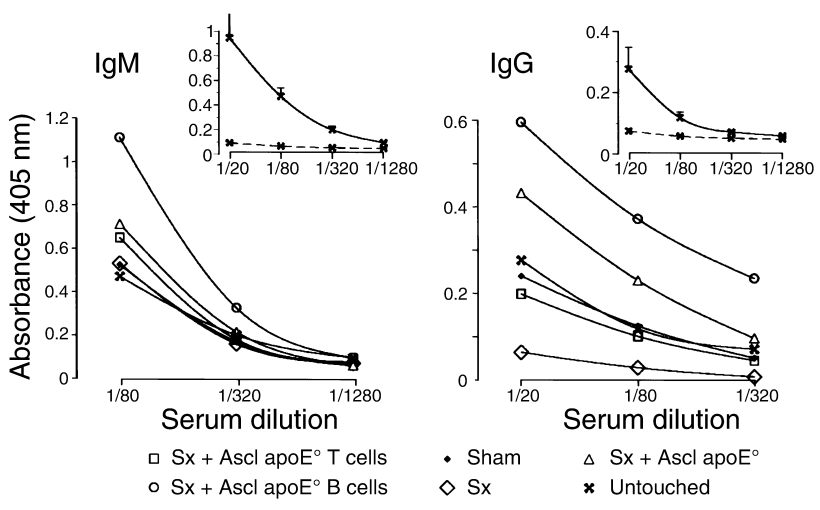

Figure 3

Effect of splenectomy and cell transfer on antibody titers to MDALDL. ELISA of IgM and IgG antibodies to MDA-LDL was performed in splenectomized (Sx), sham-operated, and untouched apo $E^{\circ}$ mice and in Sx mice that had received total spleen cells or isolated T or B cells from atherosclerotic, 20 -week-old apoE ${ }^{\circ}$ mice. Data show binding of IgM and IgG from diluted mouse sera to MDA-LDL-coated plates (mean absorbance). Insets: ELISA of IgM and IgG antibodies to MDA-LDL (continuous lines) and $\mathrm{nLDL}$ (dashed lines) in untouched $\mathrm{apoE}^{\circ}$ mice (means $\pm \mathrm{SEM}$ ). Incubation on plates coated with native $L D L$ resulted in absorbance levels $<0.1$ in all treatment groups (data not shown). $n=4$ mice per group. 
Table 2

Homing of transferred Dil+ spleen lymphocytes to lymph nodes in apoE ${ }^{\circ}$ mice.

\begin{tabular}{lcc}
\hline Treatment & Transfer & Percent Dil+ cells \\
Splenectomy $(n=6)$ & PBS & $0.045 \pm 0.005$ \\
Sham $(n=3)$ & Dil+ spleen cells & $0.180 \pm 0.074^{\mathrm{A}}$ \\
Splenectomy $(n=6)$ & Dil+ spleen cells & $0.240 \pm 0.018^{\mathrm{A}}$
\end{tabular}

Data show the proportion of Dil+ cells in a lymphocyte light scatter gate (forward scatter + side scatter, FSC+SSC) at FACS analysis of cells from mesenteric, paraaortic and inguinal lymph nodes of recipients four weeks after i.v. injection of $60 \times 10^{6}$ spleen cells. Data show mean $\pm \mathrm{SEM}$. AStatistically significant difference from sham-operated control $(P<0.01)$.

Splenectomized mice exhibited changes in humoral immunity. They had reduced antibody titers against MDA-LDL, but transfer of B cells increased them above the level in the sham-operated host (Figure 3). T cell transfer had modest effects on antibody titers (Figure 3). Moderate differences in the concentrations of total IgG subclasses were observed between treatment groups; however, these differences did not correlate to the differences in disease severity (data not shown). Serum cholesterol values tended to be lower in mice receiving B cells, but the tendency did not reach statistical significance (Table 1).

The cellular composition of the lesions was modified after cell transfer. As shown in Figure 5, splenectomy increased not only the size but also the content of $\mathrm{CD} 4^{+}$ $\mathrm{T}$ cells in the lesions. In contrast, transfer of total spleen cells or spleen B cells from atherosclerotic mice reduced $\mathrm{CD}^{+} \mathrm{T}$ cell infiltration as well as the size of the lesions in recipient $\mathrm{apoE}^{\circ}$ mice. The percentage of $\mathrm{CD}^{+}$or I-A ${ }^{\mathrm{b}+}$ cells did not differ significantly between the groups (data not shown).

To evaluate the possible role of the atherogenic cytokine IFN- $\gamma$, we analyzed it by ELISA of serum samples. IFN- $\gamma$ levels were low in sham-operated and splenectomized $\mathrm{apoE}^{\circ}$ mice $(0.405 \pm 0.257$ and $0.528 \pm 0.208$ $\mathrm{ng} / \mathrm{ml}$, means $\pm \mathrm{SEM}$ ) and increased significantly after cell transfer in the splenectomized groups $(P<0.05$ for both $\mathrm{T}$ and $\mathrm{B}$ cell transfer). However, IFN- $\gamma$ was higher in $\mathrm{T}$ cell- than in B cell-transferred mice $(2.50 \pm 0.203$ vs. $1.29 \pm 0.415 \mathrm{ng} / \mathrm{ml})$. Therefore, circulating IFN- $\gamma$ levels did not correlate with protection against atherosclerosis.

\section{Discussion}

This study shows that atheroprotective immunity develops during the progression of atherosclerosis. This conclusion is supported by the findings that (a) removal of the spleen, a major immune organ, increased the extent and severity of atherosclerosis in $\mathrm{apoE}^{\circ}$ mice; (b) reconstitution with spleen cells from either wild-type or nonatherosclerotic, young apoE ${ }^{\circ}$ mice reduced disease in splenectomized animals; (c) transfer of spleen cells or purified B cells from atherosclerotic apo $\mathrm{E}^{\circ}$ mice not only rescued the recipients but protected them from development of advanced disease; and (d) $\mathrm{B}$ cells from atherosclerotic apo $\mathrm{E}^{\circ}$ mice reduced the extent of atherosclerosis in sham-operated as well as in splenectomized $a p o E^{\circ}$ mice.
We propose that splenectomy reduced the capacity of the apo $\mathrm{E}^{\circ}$ mice to develop atheroprotective immunity. If this were correct, one would expect that immune cells from $\mathrm{apoE}^{\circ}$ mice with severe disease would maintain an immunologic memory and contain an increased proportion of cells carrying atheroprotective immunity. This was confirmed by the finding that spleen cells from atherosclerotic $\mathrm{apo}^{\circ}$ mice reduced disease to a level significantly below that of untreated or shamoperated $\mathrm{apoE}^{\circ}$ mice.

$B$ cell transfer reduced atherosclerosis more efficiently in the splenectomized than in the intact $\mathrm{apoE}^{\circ}$ mouse. This may be due to an increased survival of transferred cells in splenectomized recipients. The lack of significant changes in antibody titers in the nonsplenectomized mice supports this possibility. By analyzing donor cells in the recipient, we found substantial differences in the distribution of such cells

a

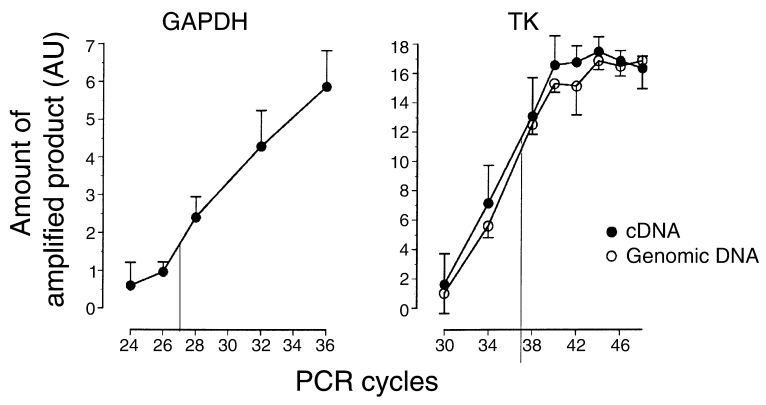

b
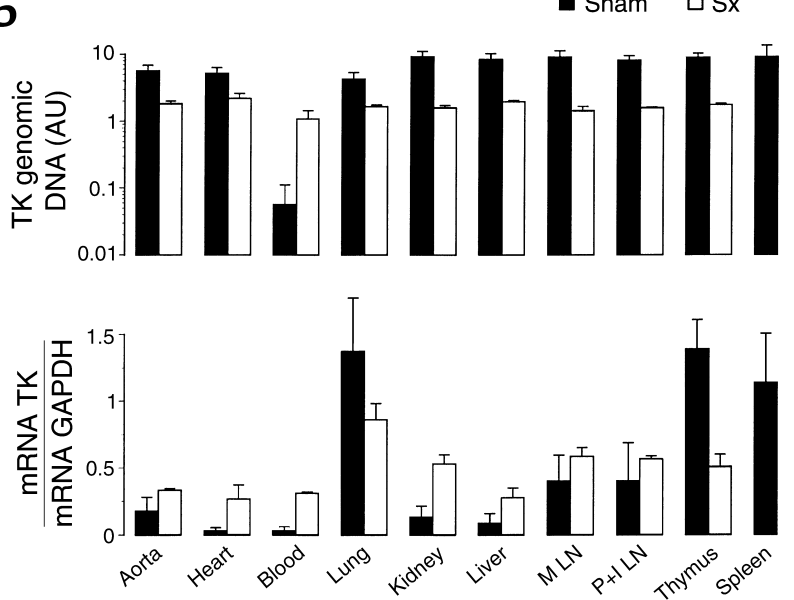

Figure 4

Long-term survival of transferred lymphocytes. (a) Kinetics of PCR reactions for GAPDH and TK. The numbers of cycles chosen for semiquantitative analysis are indicated. (b) Spleen cells of mice expressing TK under the CD4 promoter were injected into shamoperated (black bars) or splenectomized (white bars) recipients. Four weeks later, homing of transferred cells was assessed by PCR analysis of the TK gene in DNA extracts (reflecting infiltrating donor cells) and RT-PCR analysis of TK mRNA in RNA extracts (reflecting infiltrating T cells) of different organs. TK RT-PCR data were normalized to GAPDH mRNA levels determined by RT-PCR (mean $\pm \mathrm{SEM}, n=4$ mice per group). M, mesenteric; $\mathrm{P}+\mathrm{I}$, para-aortic and inguinal; $L N$, lymph nodes. 

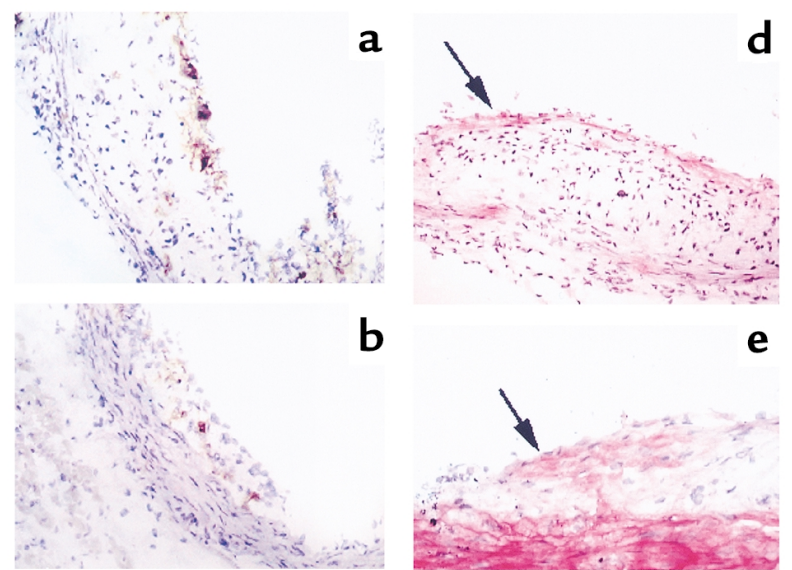

b

e
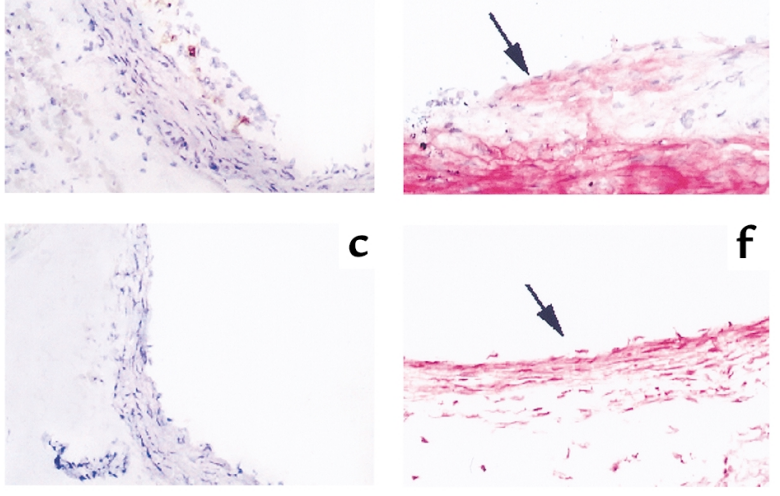

C
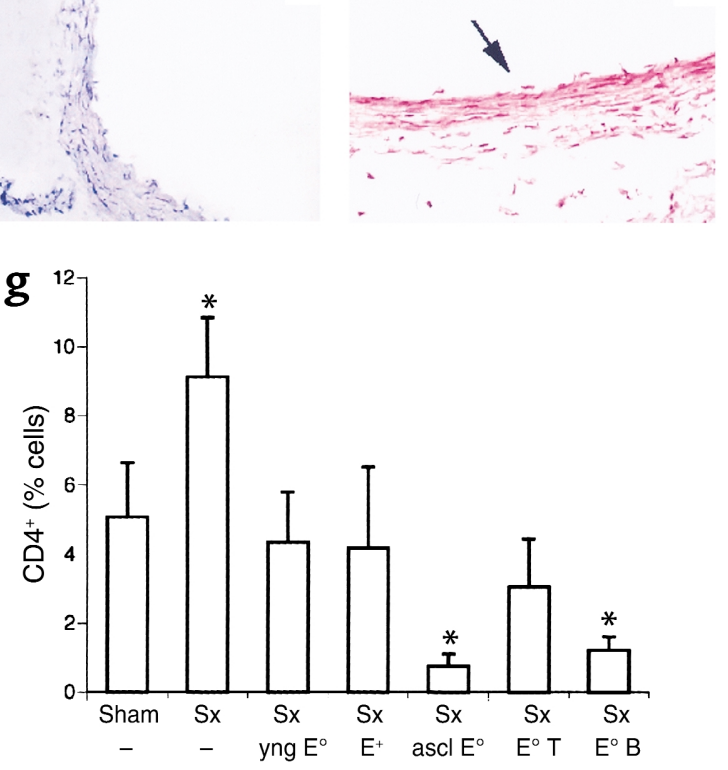

\section{Figure 5}

Transfer of B cells reduces accumulation of $C D 4^{+} T$ cells and $\alpha S M$ actin $^{+}$smooth muscle cells. (a-c) Immunoperoxidase staining of $\mathrm{CD}^{+} \mathrm{T}$ cells in aortic lesions of $(\mathbf{a})$ splenectomized apo $^{\circ}$ mice, (b) splenectomized apo $\mathrm{E}^{\circ}$ mice reconstituted with $\mathrm{CD} 4^{+} \mathrm{T}$ cells from atherosclerotic apo $\mathrm{E}^{\circ}$ mice, and (c) splenectomized apo $\mathrm{E}^{\circ}$ mice reconstituted with $B$ cells from atherosclerotic apo $E^{\circ}$ mice ( $\times 100$ magnification). Significant infiltrates of $C D 4^{+}$cells are present in $\mathbf{a}$ and $\mathbf{b}$ but not in $\mathbf{c}$. ( $\mathbf{d}-\mathbf{f})$ Immunophosphatase staining of $\alpha S M$-actin in aortic lesions of $(\mathbf{d})$ splenectomized apoE ${ }^{\circ}$ mice $(\times 100)$, (e) splenectomized apo $\mathrm{E}^{\circ}$ mice reconstituted with $\mathrm{CD}^{+}$ $T$ cells from atherosclerotic apo ${ }^{\circ}$ mice $(\times 200)$, and $(\mathbf{f})$ splenectomized apo $\mathrm{E}^{\circ}$ mice reconstituted with $\mathrm{B}$ cells from atherosclerotic apo $\mathrm{E}^{\circ}$ mice $(\times 100)$. In $(\mathbf{d})$, an $\alpha \mathrm{SM}$-actin ${ }^{+}$cap is present in the lesion (arrow), and the media have reduced $\alpha \mathrm{SM}$-actin staining (compare with $\mathbf{e}$ and $\mathbf{f}$ ). In $\mathbf{e}$, the arrow points to $\alpha S M$-actin ${ }^{+}$ cells in the lesion. In f, only a few intimal cells are discerned (arrow) and there is strong medial $\alpha S M$-actin staining. (g) Quantification of $\mathrm{CD}^{+} \mathrm{T}$ cells. Increased infiltration of $\mathrm{CD} 4^{+} \mathrm{T}$ cells was found in lesions of splenectomized mice, while animals protected by adoptive transfer had fewer infiltrating $C D 4^{+}$cells. Data are expressed as percent of all hematoxylin-stained cells in the lesions. $n=8($ sham $), 7(\mathrm{Sx}), 4\left(\right.$ yng E $\left.{ }^{\circ}\right), 4\left(\mathrm{E}^{+}\right), 6\left(\operatorname{ascl} \mathrm{E}^{\circ}\right), 4\left(\mathrm{E}^{\circ} \mathrm{T}\right), 4\left(\mathrm{E}^{\circ}\right.$ B). ${ }^{*} P<0.05$ vs. sham. between organs. However, long-term survival of transferred cells was evident in sham-operated as well as splenectomized mice.

Several lines of evidence imply immune cells as pivotal in the atherosclerotic process. Reconstitution of irradiated $\mathrm{apo}^{\circ}$ mice with bone marrow cells from wild-type donors prevents disease (34-36). Although effects on cholesterol metabolism and macrophage function were of major importance for these effects, transfer of lymphocytes might also play a role. In the present study, transfer of spleen cells from wild-type apo: ${ }^{+/+} \mathrm{C} 57 \mathrm{BL} / 6 \mathrm{~J}$ mice, as well as from atherosclerotic $a \mathrm{poE}^{\circ}$ mice, reduced serum cholesterol substantially in the recipients. For instance, transfer of wild-type spleen cells led to a $32 \%$ reduction and transfer of spleen cells from atherosclerotic apoE ${ }^{\circ}$ mice to a $20 \%$ reduction in serum cholesterol levels of splenectomized recipients (Table 1). However, lesion size was reduced to a substantially greater extent by transfer of spleen cells from the atherosclerotic apoE $^{\circ}$ mice as compared with transfer of wildtype spleen cells, implying that the effect on cholesterol cannot account for the entire effect of cell transfer. This conclusion is supported by the fact that splenectomy, while increasing the extent of atherosclerosis 2.6 -fold, did not elevate serum cholesterol at all (Table 1). The effects of C57BL/6J spleen cells could be due to the transfer of some apoE, which regulates both cholesterol metabolism (35) and certain immune functions (37). The additional protective effect conferred by $\mathrm{B}$ cells, which do not express apoE, implies that, in addition to cholesterol-lowering mechanisms, adaptive immunity may play an important atheroprotective role.

At first glance, it may appear surprising that atheroprotective immunity could not prevent the disease in the control $\mathrm{apoE}^{\circ}$ mice but inhibited the progression of atherosclerosis very efficiently in recipient. However, the two situations are entirely different. In the control or sham-operated mouse, the natural immune response may act to reduce atherosclerosis but is only modestly successful. This was unmasked by splenectomy, since the removal of this B cell-enriched immune organ led to increased atherosclerosis. In the transfer experiment, in contrast, B cells that had expanded and/or undergone affinity maturation in response to atherosclerosis-related antigen(s) were introduced into the disease-prone but still healthy mouse and were present throughout the disease process. Splenectomy of the recipient prior to transfer increased lymphocyte homing to the heart and aorta as well as the frequency of circulating, transferred lymphocytes. This experimental situation therefore maximized the atheroprotective effect.

The spleen is a major site for immune reactions against circulating antigens such as oxLDL and bloodborne microbes and is the main reservoir of memory lymphocytes (25). It is by far the largest antibody-producing organ, and several types of antibodies could be involved in the atheroprotective action registered in the present study. B cells may bring about a more effective 
elimination of atherosclerosis-related antigens by producing specific antibodies. Furthermore, B cells may produce antiidiotypic antibodies that can modify the immune repertoire; such antibodies ameliorate autoimmune lupus in NZB/NZW mice $(38,39)$. Polyclonal Ig therapy may also modulate the immune repertoire and is therefore used to treat autoimmune diseases (40). We have previously reported that this therapy inhibits atherosclerosis in $\mathrm{apoE}^{\circ}$ mice (14).

Witztum and coworkers recently reported that "natural" antibodies reactive with phosphorylcholine also recognize oxLDL and block its uptake by macrophages (41). Such IgM antibodies are produced in abundance in the spleen, and the corresponding B cells can be cloned from spleen cell suspensions of $\mathrm{apoE}^{\circ}$ mice (24). It is interesting to speculate that $\mathrm{B}-1$ cells producing natural antibodies reactive with oxLDL might have been important for the atheroprotective activity of spleen B cells observed in the present study.

Our data are in line with the notion that oxLDL is an important candidate antigen in atherosclerosis (3-5). The disease-aggravating effect of splenectomy was associated with a significant reduction of antibody titers against MDA-LDL, while the protective effect of $B$ cells from diseased mice was associated with increased antibody titers. Anti-oxLDL antibodies may be important for clearance of oxLDL, and hyperimmunization with oxLDL results in high antibody titers and protection against atherosclerosis in hypercholesterolemic rabbits $(16,17)$ and $\mathrm{apoE}^{\circ}$ mice $(18)$. The correlation is limited between antibody titers and extent of protection against atherosclerosis in oxLDL-immunized LDL receptordeficient mice (19); however, we have recently found that the titer of IgG antibodies correlates significantly to protection in $\mathrm{apoE}^{\circ}$ mice (29). In the present study, there was a nonsignificant tendency toward lower serum cholesterol in mice receiving spleen cells or B cells. It will be interesting to determine whether antibodies produced by such cells act to reduce cholesterol, for example by increasing the clearance of modified LDL.

Besides producing antibodies, activated antigenspecific $B$ cells can present antigens to $T$ cells and secrete cytokines. Interestingly, treatment with an encephalitogenic myelin basic protein-derived peptide in a conjugate targeted to $B$ cells protected rats from autoimmune encephalomyelitis on concomitant challenge with myelin basic protein in Freund's adjuvant (23). Therefore, the role of B cells in atheroprotection may not be limited to antibody production but could also involve more complex activities in the immune network. Indeed, the substantial effect of B cell transfer on the content of $\mathrm{CD} 4^{+} \mathrm{T}$ cells in the lesions shows that this treatment affected the local immune activity at this site.

Proatherogenic activities of the immune system have been associated with inflammatory responses elicited by $\mathrm{T}$ cells. We have recently shown that infusion of $\mathrm{CD}^{+} \mathrm{T}$ cells from atherosclerotic donors aggravates atherosclerosis in immunodeficient apoE ${ }^{\circ}$-SCID mice (13). In the present study, the effects of $T$ cells were less striking than those of B cells. In the splenectomized host, T cell transfer rescued recipients from the disease-aggravating effect of splenectomy but did not affect lesion development in young, sham-operated $\mathrm{apoE}^{\circ}$ mice.

The apparent discrepancy between our results in SCID mice and the present study can be explained by the differences in the two models with regard to immunocompetence of the host.

Firstly, splenectomized recipients are still immunocompetent, and transferred $\mathrm{T}$ cells enter a regulatory immune network. In contrast, $\mathrm{apoE}^{\circ}$-SCID mice lack regulatory immune cells that could control the activity of the transferred $\mathrm{T}$ cells. Indeed, in an autoimmune encephalomyelitis model, the pathogenic potential of antigen-specific T cells is greater in SCID mice than in immunocompetent mice (42). Secondly, the possible effect of $\mathrm{CD}^{+}$cell transfer has not been assessed in apo ${ }^{\circ}$-SCID mice. In the present study, the infused $\mathrm{T}$ cell preparations contained about $60 \% \mathrm{CD}^{+}$and about $40 \% \mathrm{CD}^{+} \mathrm{T}$ cells. It is possible that regulatory/suppressive properties of $\mathrm{CD}^{+}$cells may explain part of the rescue effect of $\mathrm{T}$ cell transfer in splenectomized mice.

It has been suggested that the deleterious effect of $\mathrm{T}$ cells in atherosclerosis could depend on a Th1 deviation of the immune response $(3,11,30,43,44)$. In the present study, the lack of correlation between the level of the Th 1 cytokine IFN- $\gamma$ and the extent of atherosclerosis in the treatment groups makes it less likely that a systemic immune deviation could account for the effect on atherosclerosis. However, it cannot be excluded that B cell transfer led to qualitative as well as quantitative changes in the $\mathrm{CD}^{+} \mathrm{T}$ cell population of the atherosclerotic lesion. Thus, local as well as systemic reactions may account for the dramatic effects of immune cell transfer described in this study.

In conclusion, our data demonstrate that the immune response developed by $B$ cells of the spleen during atherosclerosis is protective in the $\mathrm{apoE}^{\circ}$ mouse model. Strategies to enhance such atheroprotective immunity could be a new approach for prevention and/or treatment of atherosclerosis.

\section{Acknowledgments}

We thank Ingrid Törnberg, Kristina Edwardsson, Jamila Laschet, and Inger Bodin for technical assistance and Anders Hamsten for providing lipoproteins. This work was supported by the Swedish Medical Research Council (project no. 6816); the Heart-Lung Foundation; and Johnson, Hedlund, Söderberg, and King GustafV Anniversary Funds. G. Caligiuri was the recipient of a fellowship from the European Society of Cardiology and A. Nicoletti of a Marie Curie fellowship from the European Union.

1. Ross, R. 1999. Atherosclerosis: an inflammatory disease. N. Engl. J. Med. 340:115-126.

2. Jonasson, L., Holm, J., Skalli, O., Bondjers, G., and Hansson, G.K. 1986. Regional accumulations of T cells, macrophages, and smooth muscle cells in the human atherosclerotic plaque. Arteriosclerosis. 6:131-138.

3. Stemme, S., et al. 1995. T lymphocytes from human atherosclerotic plaques recognize oxidized LDL. Proc. Natl. Acad. Sci. USA. 92:3893-3897. 
4. Ylä-Herttuala, S., et al. 1994. Rabbit and human atherosclerotic lesions contain IgG that recognizes epitopes of oxidized LDL. Arterioscler. Thromb. 14:32-40.

5. Salonen, J.T., et al. 1992. Autoantibody against oxidised LDL and progression of carotid atherosclerosis. Lancet. 339:883-887.

6. Xu, Q., et al. 1993. Association of serum antibodies to heat-shock protein 65 with carotid atherosclerosis. Lancet. 341:255-259.

7. Saikku, P., et al. 1988. Serological evidence of an association of a novel Chlamydia, TWAR, with chronic coronary heart disease and acute myocardial infarction. Lancet. 2:983-986.

8. Piedrahita, J.A., Zhang, S.H., Hagaman, J.R., Oliver, P.M., and Maeda, N 1992. Generation of mice carrying a mutant apolipoprotein E gene inactivated by gene targeting in embryonic stem cells. Proc. Natl. Acad. Sci. USA. 89:4471-4475.

9. Plump, A.S., et al. 1992. Severe hypercholesterolemia and atherosclerosis in apolipoprotein E-deficient mice created by homologous recombination in ES cells. Cell. 71:343-353.

10. Dansky, H.M., Charlton, S.A., Harper, M.M., and Smith, J.D. 1997. T and B lymphocytes play a minor role in atherosclerotic plaque formation in the apolipoprotein E-deficient mouse. Proc. Natl. Acad. Sci. USA. 94:4642-4646.

11. Gupta, S., et al. 1997. IFN-gamma potentiates atherosclerosis in ApoE knock-out mice. J. Clin. Invest. 99:2752-2761.

12. Lutgens, E., et al. 1999. Requirement for CD154 in the progression of atherosclerosis. Nat. Med. 5:1313-1316.

13. Zhou, X., Nicoletti, A., Elhage, R., and Hansson, G.K. 2000. Transfer of CD4+ $\mathrm{T}$ cells aggravates atherosclerosis in immunodeficient apoE knockout mice. Circulation. 102:2919-2922.

14. Nicoletti, A., Kaveri, S., Caligiuri, G., Bariety, J., and Hansson, G.K. 1998 Immunoglobulin treatment reduces atherosclerosis in apo E knockout mice. J. Clin. Invest. 102:910-918.

15. Mach, F., Schonbeck, U., Sukhova, G.K., Atkinson, E., and Libby, P. 1998. Reduction of atherosclerosis in mice by inhibition of CD40 signalling. Nature. 394:200-203.

16. Palinski, W., Miller, E., and Witztum, J.L. 1995. Immunization of low density lipoprotein (LDL) receptor-deficient rabbits with homologous malondialdehyde-modified LDL reduces atherogenesis. Proc. Natl. Acad. Sci. USA. 92:821-825.

17. Nilsson, J., et al. 1997. Immunization with homologous oxidized low density lipoprotein reduces neointimal formation after balloon injury in hypercholesterolemic rabbits. J. Am. Coll. Cardiol. 30:1886-1891.

18. George, J., et al. 1998. Hyperimmunization of apo-E-deficient mice with homologous malondialdehyde low-density lipoprotein suppresses early atherogenesis. Atherosclerosis. 138:147-152.

19. Freigang, S., Hörkkö, S., Miller, E., Witztum, J.L., and Palinski, W. 1998 Immunization of LDL receptor-deficient mice with homologous malondialdehyde-modified and native LDL reduces progression of atherosclerosis by mechanisms other than induction of high titers of antibodies to oxidative neoepitopes. Arterioscler. Thromb. Vasc. Biol. 18:1972-1982.

20. Zhou, X., Caligiuri, G., Hamsten, A., Lefvert, A.K., and Hansson, G.K. 2001. Protection against atherosclerosis by LDL immunization is associated with $\mathrm{T}$ cell dependent IgG antibodies in apoE-deficient mice. Arterioscler. Thromb. Vasc. Biol. 21:108-114.

21. Mallat, Z., et al. 1999. Protective role of interleukin-10 in atherosclerosis. Circ. Res. 85:e17-e24.

22. Pinderski Oslund, L.J., et al. Interleukin-10 blocks atherosclerotic events in vitro and in vivo. Arterioscler. Thromb. Vasc. Biol. 19:2847-2853.

23. Saoudi, A., Simmonds, S., Huitinga, I., and Mason, D. 1995. Prevention of experimental allergic encephalomyelitis in rats by targeting autoantigen to B cells: evidence that the protective mechanism depends on changes in the cytokine response and migratory properties of the autoantigen-specific T cells. J. Exp. Med. 182:335-344.

24. Palinski, W., et al. 1996. Cloning of monoclonal autoantibodies to epi- topes of oxidized lipoproteins from apolipoprotein E-deficient mice. Demonstration of epitopes of oxidized low density lipoprotein in human plasma. J. Clin. Invest. 98:800-814.

25. Brown, A.R. 1992. Immunological functions of splenic B-lymphocytes. Crit. Rev. Immunol. 11:395-417.

26. Stark, J.M., Matthews, N., and Locke, J. 1980. Immunogenicity of lipidconjugated antigens. II. Anti-complementary activity and antigen trapping in the spleen. Immunology. 39:353-360.

27. Smith, T.F., and Johnston, R.B., Jr. 1979. Functions of the spleen in host defense against infection. Am. J. Pediatr. Hematol. Oncol. 1:355-362.

28. Sullivan, J.L., et al. 1978. Immune response after splenectomy. Lancet. 1:178-181.

29. Zhou, X., Stemme, S., and Hansson, G.K. 1996. Evidence for a local immune response in atherosclerosis. CD4+ T cells infiltrate lesions of apolipoprotein-E-deficient mice. Am. J. Pathol. 149:359-366.

30. Zhou, X., Paulsson, G., Stemme, S., and Hansson, G.K. 1998. Hypercholesterolemia is associated with a T helper (Th) $1 / \mathrm{Th} 2$ switch of the autoimmune response in atherosclerotic apo E-knockout mice. J. Clin. Invest. 101:1717-1725.

31. Craig, W.Y., Poulin, S.E., Nelson, C.P., and Ritchie, R.F. 1994. ELISA of IgG antibody to oxidized low-density lipoprotein: effects of blocking buffer and method of data expression. Clin. Chem. 40:882-888.

32. Salmon, P., Boyer, O., Lores, P., Jami, J., and Klatzmann, D. 1996. Characterization of an intronless CD4 minigene expressed in mature CD4 and CD8 T cells, but not expressed in immature thymocytes. J. Immunol. 156:1873-1879.

33. Reinhardt, R.L., et al. 2001. Visualizing the generation of memory CD4 T cells in the whole body. Nature. 410:101-105.

34. Boisvert, W.A., Spangenberg, J., and Curtiss, L.K. 1995. Treatment of severe hypercholesterolemia in apolipoprotein E-deficient mice by bone marrow transplantation. J. Clin. Invest. 96:1118-1124.

35. Linton, M.F., Atkinson, J.B., and Fazio, S. 1995. Prevention of atherosclerosis in apolipoprotein E-deficient mice by bone marrow transplantation. Science. 267:1034-1037.

36. Van Eck, M., et al. 1997. Bone marrow transplantation in apolipoprotein E-deficient mice. Effect of ApoE gene dosage on serum lipid concentrations (beta)VLDL catabolism, and atherosclerosis. Arterioscler. Thromb. Vasc. Biol. 17:3117-3126.

37. Laskowitz, D.T., Lee, D.M., Schmechel, D., and Staats, H.F. 2000. Altered immune responses in apolipoprotein E-deficient mice. J. Lipid Res. 41:613-620.

38. Hahn, B.H., and Ebling, F.M. 1984. Suppression of murine lupus nephritis by administration of an anti-idiotypic antibody to anti-DNA. J. Immunol. 132:187-190.

39. Morland, C., et al. 1991. Anti-idiotype and immunosuppressant treatment of murine lupus. Clin. Exp. Immunol. 83:126-132.

40. Kazatchkine, M.D., and Kaveri, S.V. 1999. Immunomodulation of autoimmune disease with normal polyspecific immunoglobulin $G$ (intravenous immunoglobulin). In The decade of autoimmunity. Y. Shoenfeld, editor. Elsevier Science. Amsterdam, The Netherlands. 409-419.

41. Shaw, P.X., et al. 2000. Natural antibodies with the T15 idiotype may act in atherosclerosis, apoptotic clearance, and protective immunity. J. Clin. Invest. 105:1731-1740.

42. Jones, R.E., Mass, M., and Bourdette, D.N. 1999. Myelin basic proteinspecific $\mathrm{T}$ lymphocytes induce chronic relapsing experimental autoimmune encephalomyelitis in lymphocyte-deficient (SCID) mice. J. Neuroimmunol. 93:92-101.

43. Uyemura, K., et al. 1996. Cross-regulatory roles of interleukin (IL)-12 and IL-10 in atherosclerosis. J. Clin. Invest. 97:2130-2138.

44. Laurat, E., et al. 2001. In vivo downregulation of T helper cell 1 immune responses reduces atherogenesis in apolipoprotein E-knockout mice. Circulation. 104:197-202. 